\title{
Prognostic relevance of high pretreatment CA125 levels in primary serous ovarian cancer
}

\author{
ROBERT BACHMANN ${ }^{1}$, SARA BRUCKER ${ }^{2}$, ANNETTE STÄBLER $^{3}$, BERNHARD KRÄMER $^{2}$, \\ RUTH LADURNER $^{1}$, ALFRED KÖNIGSRAINER ${ }^{1}$, DIETHELM WALLWIENER ${ }^{2}$ and CORNELIA BACHMANN ${ }^{2}$ \\ ${ }^{1}$ Department of General, Visceral and Transplant Surgery, University Hospital Tübingen; \\ ${ }^{2}$ Department of Obstetrics and Gynecology, University of Tuebingen; ${ }^{3}$ Institute of Pathology and \\ Neuropathology and Comprehensive Cancer Center Tübingen, University Hospital Tübingen, \\ Eberhard-Karls-University, D-72076 Tübingen, Germany
}

Received December 14, 2019; Accepted August 12, 2020

DOI: $10.3892 / \mathrm{mco} .2020 .2170$

\begin{abstract}
The objective of the present study was to analyze the prognostic relevance of pretreatment serum CA125 $\geq 500 \mathrm{U} / \mathrm{ml}$ and its role as a non-invasive factor for estimating optimal cytoreduction $(\leq 1 \mathrm{~cm})$ in primary serous ovarian cancer. Clinicopathological parameters and CA125 levels prior to primary cytoreductive surgery were retrospectively evaluated in all 261 consecutive patients with primary epithelial ovarian cancer from a single centre. Inclusion criteria were existing preoperative CA125 level, serous ovarian cancer and performed full primary treatment (surgery/platinum-based chemotherapy). A total of 136 patients met the criteria. Among them, 74 patients had CA125 $\geq 500 \mathrm{U} / \mathrm{ml}$. The other 62 patients that met the aforementioned criteria and had CA125 <500 U/ml were defined as controls. The present study tested cut-off CA125 values to detect subgroups affecting prognosis. The goal was to evaluate patients with optimal cytoreduction $(\mathrm{R} \leq 1 \mathrm{~cm})$. Univariate analyses were performed with PASW to identify clinicopathological parameters associated with the pretreatment CA125 level. For survival analyses, a cut-off-value of CA125 $\geq 500 \mathrm{U} / \mathrm{ml}$ was used to identify the association between preoperative CA125 levels, resection status and prognosis. To test significant differences between examined groups, Student's t-test and the Mann-Whitney test
\end{abstract}

Correspondence to: Dr Cornelia Bachmann, Department of Obstetrics and Gynecology, University of Tuebingen, Calwer Street 7, D-72076 Tübingen, Germany

E-mail: cornelia.bachmann@med.uni-tuebingen.de

Abbreviations: CA125, cancer antigen125; FIGO, Fédération Internationale de Gynécologie et d'Obstétrique; R, resection status; HE4, human epididymis protein 4; CT-scan, computer tomography; AOC, advanced ovarian cancer; AGO, (Arbeitsgemeinschaft) society gynecologic oncology

Key words: ovarian cancer, CA125, prognosis, optimal cytoreduction, residual tumour mass, histology, cut-off were used. $\mathrm{P}<0.05$ was considered to indicate a statistically significant difference. Significantly worse prognosis in terms of overall survival $(\mathrm{P}=0.023)$ and progression-free survival $(\mathrm{P}=0.011)$ was detected in the $\mathrm{CA} 125 \geq 500 \mathrm{U} / \mathrm{ml}$ group of optimally cytoreduced patients compared with in the CA125 $<500 \mathrm{U} / \mathrm{ml}$ group. The complete cytoreduction rate was higher in CA125<500 U/ml (33.9\%) vs. CA125 2500 U/ml (21.6\%). A CA125 level $>1,404 \mathrm{U} / \mathrm{ml}$ had a higher rate of suboptimal cytoreduction (32.4\%) compared with lower CA125 levels. A pretreatment CA125 level $\geq 500 \mathrm{U} / \mathrm{ml}$ had significantly worse prognostic impact after optimal cytoreduction compared with CA125 $<500 \mathrm{U} / \mathrm{ml}$. The higher the CA125 level the higher the suboptimal cytoreduction rate. Patients with CA125 $\geq 500 \mathrm{U} / \mathrm{ml}$ may be candidates for an initial laparoscopic approach to specify resectability and to determine how to proceed. Overall, CA125 levels appear to be helpful in predicting suboptimal cytoreductive surgery for patients with primary ovarian cancer, but should be interpreted together with clinical and radiologic findings. This may improve defining the optimal treatment strategy in these patients.

\section{Introduction}

Optimal cytoreduction achieving residual tumour $\leq 1 \mathrm{~cm}$ followed by a platinum-based chemotherapy has best prognostic impact in advanced epithelial ovarian cancer (1). Optimal time of surgery (up-front vs. interval debulking) is still discussed (2). A study demonstrated that patients with primarily inoperable advanced ovarian cancer who received neoadjuvant chemotherapy followed by interval debulking surgery have no inferior benefit compared to patients with primary cytoreductive surgery (2). Most important was complete cytoreduction with residual tumour $=0 \mathrm{~mm}(2)$.

CA125 level (Cancer antigen 125) has revealed an important role in monitoring patients with ovarian cancer and its importance at initial diagnosis of ovarian cancer is still controversial $(3,4)$. Measurement of CA125 level is performed preoperatively in patients who are suspected of having or are diagnosed with ovarian cancer. At initial diagnosis CA125 levels (normal range $<35 \mathrm{U} / \mathrm{ml}$ ) are elevated in about $80 \%$ of epithelial ovarian cancer patients and correlate well with response to 
therapy, disease progression or recurrence (3-9). Known is the greater CA125 levels the more advanced stages (10).

A previous study demonstrated that a CA125 level $>550 \mathrm{U} / \mathrm{ml}$ before neoadjuvant chemotherapy is an independent risk factor of suboptimal debulking at interval debulking surgery (11). Selection criteria identifying patients who will benefit from interval debulking surgery are required. Thus, the question arises if there is a CA125 level an optimal cytoreduction cannot be achieved while primary surgery in advanced stages and these patients may benefit from interval debulking surgery.

Some studies assessed the CA125 level to predict the extent of cytoreduction (12-14). A previous study demonstrated a significant positive correlation between optimal cytoreduction and CA125 level; patients with optimal cytoreduction had a significant lower CA125 level than patients after suboptimal cytoreduction (12). They concluded CA125 level is 'a weak positive and negative factor for predicting cytoreductive surgery' (12). Another study demonstrated a significant higher CA125 level in suboptimal cytoreduced (mean: 1,067 U/ml) vs. optimal cytoreduced patients, but concluded CA125 level is not a reliable predictor of optimal cytoreduction (13). Brockbank et al (14) recommended pretreatment CA125 level as a 'reliable component of preoperative assessment'; CA125 level was described as 'best predictor of disease suboptimally cytoreduced' and an optimal cut-off for serum CA125 as a predictor of suboptimal debulking was defined as $586 \mathrm{U} / \mathrm{ml}$ (14). A retrospective analysis comparing interval debulking surgery and up-front surgery showed improved survival after normalization of CA125 level during chemotherapy prior to interval debulking surgery compared to patients with suboptimally cytoreduction in primary surgery (15). So CA125 seems to be a good marker controlling therapy effort. A previous study demonstrated CA125 level $\geq 500 \mathrm{U} / \mathrm{ml}$ is most often correlated with advanced FIGO stages in ovarian cancer $(10,13)$ and is described as a factor optimal cytoreduction can be achieved in approximately $20 \%$ of cases (10). They concluded CA125 levels seem to be helpful in predicting suboptimal cytoreductive surgery for patients with primary ovarian cancer, but it should be interpreted together with clinical and radiologic findings (16). They defined 11 parameters (CA125 U/ml included) and evaluated a predictive score (16). They detected 3 clinical (age/CA125 $\geq 600 \mathrm{U} / \mathrm{ml} / \mathrm{ASA} 3-4$ ) and 8 radiological criteria that were significantly associated with presence of residual disease in their prospective study (16). They concluded this may improve defining optimal treatment strategy in these patients (16). Achieving suboptimal cytoreduction by laparotomy doesn't offer a survival advantage, demonstrated by Chi et al (10) with the recommendation of modifying primary surgical approach or alter the standard sequence of cytoreductive surgery and chemotherapy.

Objective was to analyze relevance of a pretreatment serum CA125 $\geq 500 \mathrm{U} / \mathrm{ml}$ as a non-invasive factor for estimating optimal cytoreduction $(\leq 1 \mathrm{~cm})$ in primary serous ovarian cancer and its prognostic relevance. We tested cut-off CA125 values to detect subgroups affecting prognosis.

\section{Materials and methods}

Description of collective. A total of 136 consecutive patients with primary epithelial ovarian cancer and existing pretreatment
CA125 levels $\geq 500 \mathrm{U} / \mathrm{ml}$ and CA125 $<500 \mathrm{U} / \mathrm{ml}$ at time of surgery treated at the department of obstetrics and gynecology treated from January 2005 through December 2012, at University Tübingen, Germany were enrolled in the study and retrospectively analyzed. Every patient underwent surgical staging or cytoreductive surgery as clinically indicated. Primary surgical treatment of epithelial ovarian cancer consisted of hysterectomy, bilateral salpingo-oophorectomy, retroperitoneal (pelvic and para-aortic) lymphadenectomy, omentectomy and resection of any metastatic lesion if possible, as well. Postoperatively, patients got platinum-based chemotherapy (6 cycles) every three weeks. Patients with neoadjuvant chemotherapy (NACT) for ovarian cancer and unlikely to be completely cytoreduced to no residual disease and even patients not capable of surgery were excluded from study. A total of 74 patients with serous cancers and CA125 level $\geq 500 \mathrm{U} / \mathrm{ml}$ who underwent primary cytoreductive surgery met inclusion criteria for the subgroup of patients with CA125 level beyond 500 and were enrolled. A preoperative CA125 level $\geq 500 \mathrm{U} / \mathrm{ml}$ was identified as the value with most predictive power achieving optimal cytoreduction according to Chi et al (10).

Procedure of evaluation. Objective of our manuscript was to analyze the relevance of a pretreatment serum CA125 $\geq 500 \mathrm{U} / \mathrm{ml}$ as a non-invasive factor for estimating optimal cytoreduction $(\leq 1 \mathrm{~cm})$ in primary serous ovarian cancer and its prognostic relevance. We tested cut-off CA125 values to detect subgroups affecting prognosis. The preoperative CA125 level $\geq 500 \mathrm{U} / \mathrm{ml}$ we applied was identified as the value with most predictive power achieving optimal cytoreduction according to Chi et al (10). The lowest CA125 level in this subgroup was $500 \mathrm{U} / \mathrm{ml}$. The range of CA125 level in the cohort was 500-48,470 U/ml. As described in materials and methods objective was to analyze the highest CA125 level optimal cytoreduction could be achieved. To determine the ability of the preoperative serum CA125 level to predict optimal cytoreduction, the true-positive rate was defined as percentage of suboptimally cytoreduced patients who had a preoperative serum CA-125 level above the median CA125 level 1,404.5 U/ml (range 501-48,470 U/ml). Based on our results (comparison of subgroups with $\mathrm{CA} 125>500 \mathrm{U} / \mathrm{ml}$ with median 1,404 U/ml without significant impact based on CA125 level) aim was evaluate the impact of CA125 level on OS and PFS in ovarian cancer patients with lower CA125 levels and comparing results with each other.

Therefore, we additionally identified patients with same characteristics and CA125 $<500 \mathrm{U} / \mathrm{ml}$ to compare groups and impact of CA125 on OS and PFS with CA125 level above and below $500 \mathrm{U} / \mathrm{ml}$.

Age was 62 years in median (range: $38-81$ years). Patients' individual records were reviewed and the following information abstracted: Age at time of diagnosis, pretreatment CA125 level, residual disease at completion of procedure, final histopathologic diagnosis, node involvement, histologic grade, prognostic impact (PFS, OS). The value CA125 $>35 \mathrm{U} / \mathrm{ml}$ was defined as an elevated level. Tumour stage was classified according to FIGO classification (17). All surgical pathologic samples were examined by a gynecological pathologist. The histological diagnosis was classified according to 
FIGO-classification (17). Extent of residual tumour mass was taken from surgical reports and was subdivided in following groups: $\mathrm{R}=0 \mathrm{~mm} ; \mathrm{R}>0 \mathrm{~cm}$ to $1 \mathrm{~cm} ; \mathrm{R}>1 \mathrm{~cm}$. Optimal cytoreduction was defined as being attained when diameter of largest residual tumor nodule remaining at end of procedure measured less than or equal to $1 \mathrm{~cm}$. Median follow up was 55 months.

Control group. Out of the above mentioned cohort of 136 patients with advanced FIGO stages a control group was defined with same inclusion criteria and CA125 level $<500 \mathrm{U} / \mathrm{ml}$. Therefore, 62 patients were included and had similar distribution of parameters like FIGO, node involvement, histological grade, residual tumour mass (Table I).

Statistical analysis. Univariate analyses were performed using PASW (Version 26 SPSS Inc.). Results are reported as medians with the 5 and $95 \%$ upper and lower quartiles (CI). The results are expressed as means, standard deviations, minimums, maximums and percentages. Survival curves were calculated using Kaplan-Meier analyses for OS to calculate hazard ratio (HR) and 95\% CI. The log-rank test was used to test for significant differences between the groups. P-values $<0.05$ were considered statistically significant. Data were compared with above mentioned control group after evaluation in same way.

\section{Results}

Evaluation of collective. All enrolled patients with CA125 level $\geq 500 \mathrm{U} / \mathrm{ml}$ had advanced FIGO stages (Table I). 89.2\% of the patients were classified to FIGO IIIC/IV; the remaining $10.8 \%$ of patients were classified to FIGO IIIA/B (Table I). Patients' characteristics are given in Table I. Data of control group CA125 $<500 \mathrm{U} / \mathrm{ml}$ are given in Table I, as well. $75.8 \%$ of control group had FIGO IIIC/IV (Table I). There was a comparable distribution of FIGO, node involvement, histological grade, residual tumour mass in study and control group ( $\mathrm{P}=$ n.s., Table I). Group CA125 $\geq 500 \mathrm{U} / \mathrm{ml}$ : Most often histologic grade $3(59.5 \%$, Table I) and node involvement (62.2\%, Table I) were detected, respectively. In patients with pretreatment CA125 level $\geq 500 \mathrm{U} / \mathrm{ml}$ optimal cytoreduction $(\mathrm{R} \leq 1 \mathrm{~cm})$ could be achieved in $74.3 \%$ of all patients and suboptimal debulking in $25.7 \%$ (Table I), respectively. In control group optimal cytoreduction was achieved in $74.2 \%$ (Table I), respectively. Rate of suboptimal cytoreduction was similar in group CA125 $<500 \mathrm{U} / \mathrm{ml}$ and CA125 $\geq 500 \mathrm{U} / \mathrm{ml}$ (25.8 vs. $25.7 \%$; Table I).

Correlation CA125 level and residual tumour. To determine the ability of the preoperative serum CA125 level to predict optimal cytoreduction, the true-positive rate (sensitivity) was defined as percentage of suboptimally cytoreduced patients who had a preoperative serum CA125 level above the median CA125 level 1,404.5 U/ml (range 501-48,470 U/ml).

The range of CA125 level $\geq 500 \mathrm{U} / \mathrm{ml}$ in serous cancers was $501-48,470 \mathrm{U} / \mathrm{ml}$ with a median of $1,404.5 \mathrm{U} / \mathrm{ml}$. The range of CA125 level associated with optimal cytoreduction was 501-16,062 U/ml (Table II). The correlation of CA125 level and residual tumour mass showed highest median CA125 level in suboptimally cytoreduced patients $(2,347 \mathrm{U} / \mathrm{ml})$ with a range of $502-48,470 \mathrm{U} / \mathrm{ml}$ compared
Table I. Patients' characteristics $(n=136)$.

\begin{tabular}{|c|c|c|c|}
\hline Parameter & $\begin{array}{c}\text { CA125 } \\
\geq 500 \mathrm{U} / \mathrm{ml}\end{array}$ & $\begin{array}{c}\text { CA125 } \\
<500 \mathrm{U} / \mathrm{ml}\end{array}$ & P-value \\
\hline FIGO stage, n (\%) & & & 0.045 \\
\hline IIIA/B & $8(10.8)$ & $15(24.2)$ & \\
\hline IIIC & $49(66.2)$ & $40(64.5)$ & \\
\hline IV & $17(23.0)$ & $7(11.3)$ & \\
\hline Histologic grade, $\mathrm{n}(\%)$ & & & 0.222 \\
\hline $\mathrm{G} 1 / 2$ & $30(40.5)$ & $31(50)$ & \\
\hline G3 & $44(59.5)$ & $31(50)$ & \\
\hline \multicolumn{4}{|c|}{ Histological subtype, n (\%) } \\
\hline Serous & $74(100)$ & $62(100)$ & \\
\hline R-status, n (\%) & & & 0.343 \\
\hline $\mathrm{R}=0 \mathrm{~mm}$ & $16(21.6)$ & $21(33.9)$ & \\
\hline $\mathrm{R}>0 \mathrm{~mm}-\leq 1 \mathrm{~cm}$ & $39(52.7)$ & $25(40.3)$ & \\
\hline $\mathrm{R}>1 \mathrm{~cm}$ & $19(25.7)$ & $16(25.8)$ & \\
\hline N-status, n (\%) & & & 0.191 \\
\hline No & $13(17.5)$ & $18(29.0)$ & \\
\hline $\mathrm{N}+$ & $46(62.2)$ & $36(58.1)$ & \\
\hline $\mathrm{Nx}$ & $15(20.3)$ & $8(12.9)$ & \\
\hline CA125-level, U/ml & $74(100)$ & $62(100)$ & \\
\hline
\end{tabular}

Univariate analysis of 74 patients with CA125 level $\geq 500 \mathrm{U} / \mathrm{ml}$ and 62 patients with CA125 level $<500 \mathrm{U} / \mathrm{ml}$. The log-rank test was used to test for significant differences between the groups. $\mathrm{P}<0.05$ was considered to indicate a statistically significant difference.

Table II. Pretreatment CA125 level $\geq 500 \mathrm{U} / \mathrm{ml}$ in association with residual tumor mass of 74 patients with primary serous ovarian cancer.

\begin{tabular}{lcc}
\hline Resection status & $\begin{array}{c}\text { CA125 level U/ml } \\
\text { [median (range) }\end{array}$ & P-value \\
\hline $\mathrm{R}=0 \mathrm{~mm}$ & $1,332.5(543-7,249)$ & 0.061 \\
$\mathrm{R}>0 \mathrm{~mm}-\leq 1 \mathrm{~cm}$ & $1,250(501-16,062)$ & \\
$\mathrm{R}>1 \mathrm{~cm}$ & $2,347(502-8,470)$ & \\
\hline
\end{tabular}

The log-rank test was used to test for significant differences between the groups. $\mathrm{P}<0.05$ was considered to indicate a statistically significant difference.

to patients with complete cytoreduction $(\mathrm{R}=0 \mathrm{~mm})$ and $\mathrm{R}>0 \mathrm{~mm}-\leq 1 \mathrm{~cm}(1,332.5$ vs. $1,250 \mathrm{U} / \mathrm{ml}$; Table II) without a significant difference (Table II), respectively. In median CA125 level of patients with $\mathrm{R}>0 \mathrm{~mm}-\leq 1 \mathrm{~cm}$ compared to patients after complete cytoreduction was lower (Table II), respectively. The maximum CA125 level in complete cytoreduced patients was lower compared to other groups (7,249 U/ml, Table II). The highest CA125 level was $48,470 \mathrm{U} / \mathrm{ml}$ in suboptimally debulked patients (Table II). The higher the CA125 level the higher the rate of suboptimal debulking, respectively (Table II). 
Table III. Comparison of pretreatment CA125 level after division into two groups ( $\geq 500-1,404 \mathrm{U} / \mathrm{ml} \mathrm{vs} .>1,404 \mathrm{U} / \mathrm{ml})$ and evaluation of residual tumor mass in 74 patients with primary serous ovarian cancer.

\begin{tabular}{lccr}
\hline Resection status & CA125 level $\geq 500-1,404 \mathrm{U} / \mathrm{ml}[\mathrm{n}(\%)]$ & CA125 level $>1,404 \mathrm{U} / \mathrm{ml}[\mathrm{n}(\%)]$ & P-value \\
\hline $\mathrm{R}=0 \mathrm{~mm}-\leq 1 \mathrm{~cm}$ & $30(81.1)$ & $25(67.6)$ & 0.183 \\
$\mathrm{R}>1 \mathrm{~cm}$ & $7(18.9)$ & $12(32.4)$ & \\
\hline
\end{tabular}

Univariate analysis was performed.

Table IV. Prognostic impact of CA125 level $\geq 500-1,404 \mathrm{U} / \mathrm{ml}$ vs. $>1,404 \mathrm{U} / \mathrm{ml}$ in 74 patients with serous ovarian cancer on OS and PFS (months; median, 95\% CI).

\begin{tabular}{lccr}
\hline Parameter & CA125 $\geq 500-1,404 \mathrm{U} / \mathrm{ml}$ & CA125 $>1,404 \mathrm{U} / \mathrm{ml}$ & P-value \\
\hline PFS months (median; 95\% CI) & $15.2(12.18-18.215)$ & $12.6(10.23-14.97)$ & 0.259 \\
OS months (median; 95\% CI) & $33.7(2.4-64.9)$ & $23.4(18.7-28.08)$ & 0.536 \\
\hline
\end{tabular}

Univariate analysis was performed. OS, overall survival; PFS, progression-free survival.

CA125 level $>/<500 \mathrm{U} / \mathrm{ml}$ and rate of cytoreduction. To identify a CA125 level optimal debulking could not be achieved, we evaluated the following after subdivision of groups with CA125 level $\geq 500 \mathrm{U} / \mathrm{ml}$ due to median of CA125 level: The correlation with residual tumour mass leads to following results (Table III). The group with CA125 level below median $1,404.5$ had a higher rate of optimal cytoreduction (81.1\%) compared to CA125>1,404.5 U/ml (67.6\%; Table III), respectively. The group with CA125 level $>1,404.5 \mathrm{U} / \mathrm{ml}$ had a rate of suboptimal debulking of $32.4 \%$ (Table III) without significant difference compared to CA125 level <1,404.5 (Table III).

Prognostic impact of CA125 level. The evaluation of prognostic impact on PFS and OS of CA125 level $\geq 500 \mathrm{U} / \mathrm{ml}$ leads to the following results (Table IV): CA125 level below $1,404.5 \mathrm{U} / \mathrm{ml}$ compared to CA125 level $>1,404.5 \mathrm{U} / \mathrm{ml}$ leads to longer PFS and OS without significant difference $(\mathrm{P}=$ n.s., Table IV). There was no significant difference ( $\mathrm{P}=$ n.s., Table IV. [median (range; 95\% CI)], respectively. Therefore, no significant difference is demonstrated due to the calculation of CA125 level with median 1,404.5 $\mathrm{U} / \mathrm{ml}$ regarding prognostic impact (Table IV).

Table $\mathrm{V}$ demonstrates the evaluation of CA125 level $\geq 500 \mathrm{U} / \mathrm{ml}$ subdivided in 2 groups $</>1,404.5 \mathrm{U} / \mathrm{ml}$ regarding prognostic impact on PFS and OS correlated with residual tumor mass (Table V).

There was no significant prognostic impact on PFS and OS regarding the different CA125 levels and residual tumour mass after subdivision of groups (Table V).

Complete cytoreduction has significant best impact on PFS (median 22 months; $\mathrm{P}=0.021$; Table VI) compared to $\mathrm{R}>0 \mathrm{~mm}-\leq 1 \mathrm{~cm}$ and $\mathrm{R}>1 \mathrm{~cm}$ in patients with CA125 level $\geq 500 \mathrm{U} / \mathrm{ml}$, respectively.

The comparison of study and control group leads to following results: Optimal cytoreduction in correlation with CA125 $<500 \mathrm{U} / \mathrm{ml}$ has significant better prognostic impact on OS and even PFS than patients with $\mathrm{R}>1 \mathrm{~cm}$ and CA125 $\geq 500 \mathrm{U} / \mathrm{ml}$ (OS: P=0.046; PFS: P=0.011; Table VII [median (range; 95\% CI)], respectively. Longest OS was detected in optimally cytoreduced patients with CA125 $<500 \mathrm{U} / \mathrm{ml}$ (Table VII) and has significant better prognostic impact on OS $(\mathrm{P}=0.023)$ and PFS $(\mathrm{P}=0.011)$ in optimally cytoreduced patients compared to CA125 $\geq 500 \mathrm{U} / \mathrm{ml}$ (Table VII; Fig. 1). No significant impact on OS was detected in suboptimally cytoreduced patients regarding CA125 level $(<500 \mathrm{U} / \mathrm{ml}$ vs. $\geq 500 \mathrm{U} / \mathrm{ml}$; P=n.s., Table VII). Evaluation of PFS: Significant better impact on PFS was seen in optimally cytoreduced patients and CA $125<500 \mathrm{U} / \mathrm{ml}(\mathrm{P}=0.011$; Table VII) compared to $\mathrm{CA} 125 \geq 500 \mathrm{U} / \mathrm{ml}$, respectively. Similar results were detected for PFS in suboptimally cytoreduced patients with CA125 level $<500 \mathrm{U} / \mathrm{ml}$ and CA125 $\geq 500 \mathrm{U} / \mathrm{ml}$ (Table VII) without significant difference.

Kaplan-Meier curves (Figs. 1 and 2) underline the impact on OS after subdivision of patients due to CA125 level. Fig. 1 demonstrates Kaplan-Meier curves for OS in optimally cytoreduced patients correlated with CA125 level (Fig. 1) with significant difference regarding CA125 level $<500 \mathrm{U} / \mathrm{ml}$ compared to $\mathrm{CA} 125 \geq 500 \mathrm{U} / \mathrm{ml}$ ( $\mathrm{P}=0.023$, Fig. 1). Optimally cytoreduced patients with CA125 $<500 \mathrm{U} / \mathrm{ml}$ had significant better OS than patients with CA125 level $\geq 500 \mathrm{U} / \mathrm{ml}$ and optimal cytoreduction ( $\mathrm{P}=0.023$, Fig. 1). Patients with $\mathrm{R}>1 \mathrm{~cm}$ subdivided regarding Ca125 level $\geq 500 \mathrm{U} / \mathrm{ml}$ vs. CA125 $<500 \mathrm{U} / \mathrm{ml}$ had no significant impact (P=n.s., Fig. 2) on OS.

\section{Discussion}

Best prognostic impact has optimal cytoreduction in patients with advanced ovarian cancer as shown in many previous studies $(1,2,18)$. Time of surgery is still discussed $(2,15)$. Important is the fact that suboptimally cytoreduced patients with $(\mathrm{R}>1 \mathrm{~cm})$ have similar OS regardless of residual tumor size (19). Previous studies reported rates of optimal cytoreduction with wide variation from 15 to $85 \%$ (19). Therefore, the question is if there are non-invasive factors predicting 
Table V. Prognostic impact of CA125 level $\geq 500-1,404 \mathrm{U} / \mathrm{ml}$ vs. $>1,404 \mathrm{U} / \mathrm{ml}$ on OS and PFS (months; median, 95\% CI) in 74 patients with serous ovarian cancer regarding residual tumor mass.

\begin{tabular}{|c|c|c|c|c|c|c|}
\hline \multirow[b]{2}{*}{$\begin{array}{l}\text { Resection } \\
\text { status }\end{array}$} & \multicolumn{2}{|c|}{ PFS, months (median; 95\% CI) } & \multirow[b]{2}{*}{ P-value } & \multicolumn{2}{|c|}{ OS, months (median; 95\% CI) } & \multirow[b]{2}{*}{ P-value } \\
\hline & $\begin{array}{c}\text { CA125 level } \\
\geq 500-1,404 \mathrm{U} / \mathrm{ml}\end{array}$ & $\begin{array}{l}\text { CA125 level } \\
>1,404 \mathrm{U} / \mathrm{ml}\end{array}$ & & $\begin{array}{c}\text { CA125 level } \\
\geq 500-1,404 \mathrm{U} / \mathrm{ml}\end{array}$ & $\begin{array}{l}\text { CA125 level } \\
>1,404 \mathrm{U} / \mathrm{ml}\end{array}$ & \\
\hline $\mathrm{R}=0 \mathrm{~mm}-\mathrm{s}$ & $13.73(12.7-16.8)$ & $13.47(9.7-17.2)$ & 0.475 & $22.3(12.85-31.75)$ & $24.47(22.3-26.64)$ & 0.466 \\
\hline $\mathrm{R}>1 \mathrm{~cm}$ & $33.5(23.04-43.96)$ & $12.1(10.02-14.25)$ & & $43.7(10.5-65.3)$ & $17.57(13.96-21.2)$ & \\
\hline
\end{tabular}

Univariate analysis was performed. The log-rank test was used to test for significant differences between the groups. $\mathrm{P}<0.05$ was considered to indicate a statistically significant difference. OS, overall survival; PFS, progression-free survival.

Table VI. Impact of residual tumor mass on PFS (median, $95 \% \mathrm{CI}$ ) in 74 patients with serous ovarian cancer with CA125 level $\geq 500 \mathrm{U} / \mathrm{ml}$.

\begin{tabular}{lcc}
\hline Parameter & PFS, months (median; 95\% CI) & P-value \\
\hline $\mathrm{R}=0 \mathrm{~mm}$ & $22.0(0-56.0)$ & 0.021 \\
$\mathrm{R}>0-\leq 1 \mathrm{~cm}$ & $11.6(9.3-13.9)$ & \\
$\mathrm{R}>1 \mathrm{~cm}$ & $16.0(10.9-21.06)$ & \\
\hline
\end{tabular}

PFS, progression-free survival.

complete cytoreduction to stratify patients for primary surgery vs. neoadjuvant chemotherapy.

Currently, pretreatment CA125 is the only serological biomarker routinely used in management of epithelial ovarian cancer patients (4) as a baseline value to monitor success of ovarian cancer treatment (3). CA125 level is useful in treatment monitoring in ovarian cancer and its importance at initial diagnosis of ovarian cancer is still controversial $(3,4)$. Normal CA125 level is $<35 \mathrm{U} / \mathrm{ml}$. Approximately $80 \%$ of epithelial ovarian cancer patients have elevated CA125 level ( $>35 \mathrm{U} / \mathrm{ml})$, with elevations in 50 to $60 \%$ of patients to greater than $90 \%$ in advanced FIGO stages (4). This fact corresponds to our data (Table I). CA125 level $\geq 500 \mathrm{U} / \mathrm{ml}$ showed mostly advanced FIGO stages (IIIC/IV); early FIGO stages were not detected in study (Table I). A previous study demonstrated that pretreatment CA125 level was significantly lower in patients with grade 1 serous ovarian cancer compared to those with high-grade serous ovarian cancer (6).

Known is the increasing CA125 level in advanced FIGO stages according to other studies as even shown in our analysis (Table I) $(20,21)$. Previous studies demonstrated serous ovarian cancers have highest CA125 level followed by endometrioid and clear cell types $(4,21,22)$; one study showed CA125 is not expressed in pure mucinous tumors of ovarian cancer (4). Other studies demonstrated that besides tumor characteristics CA125 levels are also influenced by several epidemiologic factors (age, parity oral contraceptives) and suggest that high BMI may influence CA125 levels independent of tumor characteristics (22). This should be mentioned in CA125 levels.

A study described a subgroup of FIGO III high-grade serous ovarian cancer patients had an enhanced survival rate with CA125 level $\geq 500 \mathrm{U} / \mathrm{ml}$ compared to lower levels (21). Against it, this correlation was not detected in our evaluation; our analysis showed the higher the CA125 level the worse the progression free survival without significant difference (Table IV). Additionally, our analysis described a significant better PFS and OS in advanced FIGO stages and CA125 level $<500 \mathrm{U} / \mathrm{ml}$ compared to CA125 $\geq 500 \mathrm{U} / \mathrm{ml}$ (Table VII). Especially significant best prognostic impact on PFS and OS was seen in optimally cytoreduced patients and CA125 level $<500 \mathrm{U} / \mathrm{ml}$ compared to CA125 $\geq 500 \mathrm{U} / \mathrm{ml}$ (Table VII). To this topic a previous study demonstrated that pretreatment CA125 level was an independent predictor of PFS in patients with advanced epithelial ovarian cancer who received a standard chemotherapy regimen, particularly in patients with debulking to a microscopic residual and in serous or endometrioid subtypes (23). Optimal cytoreduction has best prognostic impact (1) so currently a prospective study (TRUST study, AGO Germany) investigates the optimal timing of cytoreduction (up-front vs. interval-debulking) to enhance the rate of optimal cytoreduction. Selection criteria identifying patients who will benefit from interval debulking surgery are required. Pretreatment CA125 level is correlated with tumourload as demonstrated in many previous studies (5), while other studies found no association (5); achieving complete cytoreduction is correlated with it as well $(5,10)$. Many previous studies demonstrated the preoperative CA125 level can serve as a predictor of optimal tumor cytoreduction in advanced ovarian cancer. In these studies high preoperative CA125 levels were associated with decreased likelihood of achieving optimal cytoreduction, while the cutoff levels differed in them (5). Therefore, other studies demonstrated that preoperative CA125 level is no reliable predictor of optimal cytoreduction (5). A previous study demonstrated a correlation of normal CA125 level with lower recurrence rate in FIGO III/IV patients compared to FIGO III/IV patients with higher CA125 levels (5). The question arises if there is a pretreatment CA125 level predicting the achievement of optimal cytoreduction is not obtainable and rather interval debulking should be performed. A previous study found that normal pretreatment CA125 levels in ovarian cancer patients are significantly associated with lower stage/grade, optimal cytoreduction and platinum sensitivity (5). They demonstrated that patients with normal pretreatment CA125 levels had better PFS and OS compared to those with elevated CA125 levels (5) and a normal CA125 level at diagnosis of ovarian cancer is also of prognostic significance, 
Table VII. Prognostic impact of CA125 level on OS and PFS regarding residual tumor mass.

\begin{tabular}{|c|c|c|c|c|c|c|c|c|c|c|}
\hline \multirow[b]{3}{*}{$\begin{array}{l}\text { Resection } \\
\text { status }\end{array}$} & \multicolumn{4}{|c|}{ OS } & \multicolumn{5}{|c|}{ PFS } & \multirow[b]{3}{*}{ P-value } \\
\hline & \multicolumn{2}{|c|}{$\begin{array}{l}\text { CA125 level } \\
<500 \mathrm{U} / \mathrm{ml}\end{array}$} & \multicolumn{2}{|c|}{$\begin{array}{c}\text { CA125 } \\
\geq 500 \mathrm{U} / \mathrm{ml}\end{array}$} & \multirow[b]{2}{*}{ P-value } & \multicolumn{2}{|c|}{$\begin{array}{l}\text { CA125 level } \\
<500 \mathrm{U} / \mathrm{ml}\end{array}$} & \multicolumn{2}{|r|}{$\begin{array}{c}\text { CA125 } \\
\geq 500 \mathrm{U} / \mathrm{ml}\end{array}$} & \\
\hline & No. & $\begin{array}{l}\text { Months } \\
\text { (median; } \\
95 \% \mathrm{CI} \text { ) }\end{array}$ & No. & $\begin{array}{l}\text { Months } \\
\text { (median; } \\
95 \% \mathrm{CI} \text { ) }\end{array}$ & & No. & $\begin{array}{l}\text { Months } \\
\text { (median; } \\
95 \% \text { CI) }\end{array}$ & No. & $\begin{array}{l}\text { Months } \\
\text { (median; } \\
95 \% \mathrm{CI} \text { ) }\end{array}$ & \\
\hline $\mathrm{R} \leq 1 \mathrm{~cm}$ & 46 & $\begin{array}{c}60.8 \\
(50.2-80.3)\end{array}$ & 54 & $\begin{array}{c}23.4 \\
(17.23-29.57)\end{array}$ & 0.023 & 46 & $\begin{array}{c}29.43 \\
(19.49-39.38)\end{array}$ & 54 & $\begin{array}{c}13.73 \\
(11.22-16.25)\end{array}$ & 0.011 \\
\hline $\mathrm{R}>1 \mathrm{~cm}$ & 16 & $\begin{array}{c}49.37 \\
(14.22-84.52)\end{array}$ & 19 & $\begin{array}{c}47.97 \\
(4.03-91.9)\end{array}$ & 0.716 & 16 & $\begin{array}{c}17.4 \\
(14.15-20.65)\end{array}$ & 19 & $\begin{array}{c}16.0 \\
(10.94-21.1)\end{array}$ & - \\
\hline
\end{tabular}

Univariate analysis of 136 patients divided into two groups according to their CA125 level ( $<500 \mathrm{vs}$. $\geq 500 \mathrm{U} / \mathrm{ml})$ and the prognostic impact on OS and PFS [OS/PFS; months (median; 95\% CI] regarding residual tumor mass $\mathrm{R} \leq 1 \mathrm{~cm}$ and $\mathrm{R}>1 \mathrm{~cm}(\mathrm{P}=0.023$; evaluation of patients with $\mathrm{R} \leq 1 \mathrm{~cm} ; \mathrm{P}=0.716$. for patients with $\mathrm{R}>1 \mathrm{~cm}$ ). Overall, there was a significant impact on $\mathrm{OS}$ and $\mathrm{PFS}$ for $\mathrm{R} \leq 1 \mathrm{~cm}$ and $\mathrm{CA} 125<500 \mathrm{U} / \mathrm{ml}$ compared with CA125 $\geq 500 \mathrm{U} / \mathrm{ml}(\mathrm{P}=0.046)$. OS, overall survival; PFS, progression-free survival.

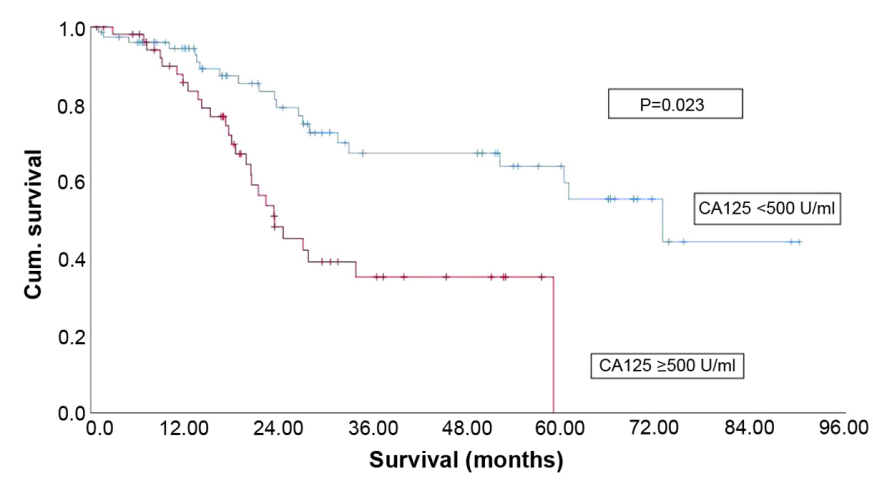

Figure 1. Kaplan-Meier curves of OS. OS of 136 patients with ovarian cancer divided into two groups according to CA125 level (CA125 $<500 \mathrm{vs} . \geq 500 \mathrm{U} / \mathrm{ml}$ ) in the subgroup of patients with residual tumour $\leq 1 \mathrm{~cm}$ $(\mathrm{P}=0.023)$. OS, overall survival.

as well (5). Our analysis demonstrated a significant better OS and PFS in optimally cytoreduced patients and CA125 level $<500 \mathrm{U} / \mathrm{ml}$ compared to higher levels (Table VII).

A previous study found in advanced ovarian cancers 'no threshold CA125 level that accurately predicted cytoreductive outcome' (24). Our analysis couldn't find a cut-off level of suboptimal debulking, but we found a association of CA125 levels and suboptimal cytoreduction (Table III). The group of CA125 1,404 U/ml had higher suboptimal cytoreduction rate than patients with CA125 $\geq 500-1,404 \mathrm{U} / \mathrm{ml}$ (Table III), without significant difference. Additionally, there was no prognostic impact on PFS and OS depending on CA125 levels $\geq 500 \mathrm{U} / \mathrm{ml}$ after subdivision of groups in $\geq 500-1,404 \mathrm{U} / \mathrm{ml}$ and CA125 $>1,404 \mathrm{U} / \mathrm{ml}$ (Table IV). They concluded with a preoperative CA-125>500 U/ml, extensive upper abdominal procedures were necessary in $50 \%$ of cases to achieve residual disease $\leq 1 \mathrm{~cm}$ compared to those with CA-125 $<500 \mathrm{U} / \mathrm{ml}(\mathrm{P}=0.001)$ (24). A previous study evaluated a predictive score to anticipate optimal cytoreduction at interval debulking surgery (11). In that study three criteria predicted independently $\mathrm{R}>0 \mathrm{~mm}$ significantly at

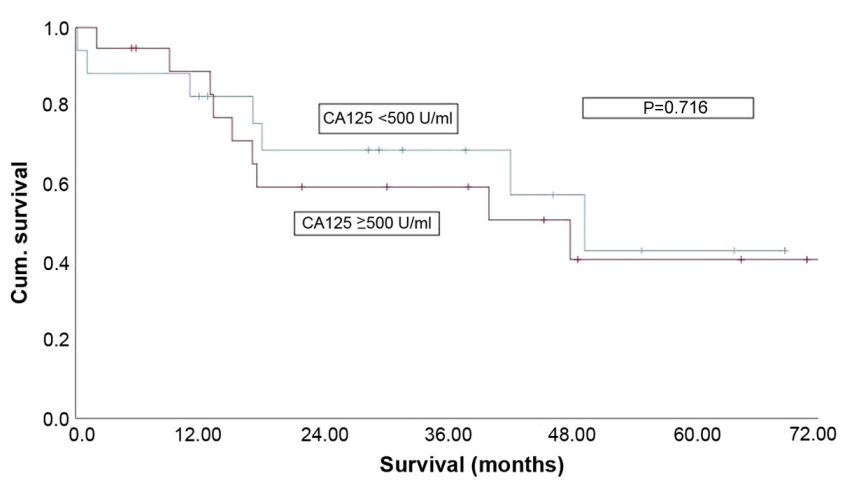

Figure 2. Kaplan-Meier curves of OS. OS of 135 patients with ovarian cancer divided into two groups depending on CA125 level (CA125 <500 vs. $\geq 500 \mathrm{U} / \mathrm{ml})$ in the subgroup of patients with residual tumor $>1 \mathrm{~cm}(\mathrm{P}=0.72)$. OS, overall survival.

interval debulking surgery: CA125 before neoadjuvant chemotherapy $>550 \mathrm{U} / \mathrm{ml}(11)$; the other criteria were age $\geq 60$ years and Peritoneal Cancer Index (PCI) $>16$ (11).

Previous studies demonstrated various CA125 levels at which optimal cytoreduction could not be achieved. Therefore, the analysis of Barlow et al (20) described that optimal cytoreduction was achieved in $\leq 40 \%$ of patients with CA125 level $\geq 4,500$ in advanced ovarian cancer patients. They concluded that preoperative serum CA125 did not reliably predict optimal cytoreduction in advanced ovarian cancer patients (20).

Our analysis demonstrated with a cut-off value of CA125 level $>1,404 \mathrm{U} / \mathrm{ml}$ optimal cytoreduction was achieved in a lower rate (67.6\%; Table III). This underlines the higher CA125 level the worse optimal cytoreduction rate.

Another study described CA125 level $\geq 500 \mathrm{U} / \mathrm{ml}$ in stage III ovarian cancer patients is most often correlated with advanced FIGO stages and is described as a factor in which cytoreduction can be achieved in approximately $20 \%$ of cases (10). In our study the rate of optimally cytoreduced patients was higher in the group of CA125 level $\geq 500 \mathrm{U} / \mathrm{ml}$ in 
advanced stages (74.3\%, Table I). Therefore, the retrospective character of our analysis and absence of some pretreatment CA125 levels should be noted. Cooper et al (13) demonstrated a 'preoperative CA 125 values less than $500 \mathrm{U} / \mathrm{ml}$ had a positive predictive value for optimal cytoreduction of $82 \%$, but a poor negative predictive value of $48 \%$. They concluded that 'preoperative CA125 is an independent risk factor for death due to disease in ovarian cancer, but not a reliable predictor of optimal cytoreduction' (13). Our analysis concluded a CA125 level $<500 \mathrm{U} / \mathrm{ml}$ has similar rate of optimal cytoreduction compared to CA125 $\geq 500 \mathrm{U} / \mathrm{ml}$ (Table I), so pretreatment CA125 level cannot predict optimal cytoreduction, but has significant prognostic impact on OS and PFS in fact of optimal cytoreduction and CA125 level $<500 \mathrm{U} / \mathrm{ml}$ compared to CA125 $\geq 500 \mathrm{U} / \mathrm{ml}$ (Table VII; Figs. 1 and 2). A previous study demonstrated that pretreatment CA125 level was not useful for predicting clinical outcome in ovarian clear cell cancer (25). Even the normalization of CA125 level after chemotherapy cycle 1 leads to decreased survival (25). Another study demonstrated similar to other previous studies pretreatment CA125 was not associated with OS, and in contrast to other studies serial CA125 measurements during chemotherapy were prognostic, with normalization before second chemotherapy cycle associated with a decreased risk of death (6). A correlation of reduction of CA125 level over the initial two cycles of platinum-based chemotherapy as a powerful independent predictor of survival for patients was detected in patients with suboptimal stage III or IV ovarian cancer as well (7). Without significant declines in CA125 after 2 cycles of platinum-based chemotherapy they have poor prognosis (7). Another previous study demonstrated that CA125 levels after the first chemotherapy cycle and even the time to normalization were the most significant prognostic factors for both OS and PFS (26). Therefore, CA125 level seems to be powerful as prognostic marker during chemotherapy.

Further, our analysis demonstrated in patients with CA125 level $\geq 500 \mathrm{U} / \mathrm{ml}$ the higher the CA125 level the lower optimal cytoreduction rate (Table III) without significant difference. Best improvement on PFS was detected in this group with complete cytoreduction independent to level of CA125 level $\geq 500 \mathrm{U} / \mathrm{ml}$ (Table VI).

Our analysis demonstrated no significant difference on PFS and $O S$ in patients with CA 125 level $\geq 500 \mathrm{U} / \mathrm{ml}$ after subdivision of group according to CA125 level 1,404.5 U/ml (Table IV).

Additionally, there was no significant difference of PFS and OS in patients with CA125 level $\geq 500 \mathrm{U} / \mathrm{ml}$ after subdivision of group according to CA125 level 1,404.5 U/ml regarding residual tumour mass (Table $\mathrm{V}$ ).

There is no predictive biomarker in ovarian cancer identifying patients who will benefit from treatment or factors which have predictive value for an optimal cytoreduction. So other groups investigated other markers and clinical parameter to predict optimal cytoreduction. Pretreatment HE4 (human epididymis protein 4) seems to be a better marker to predict optimal cytoreduction in primary surgery than CA125, but should be used in combination with clinical parameter like ascites $<500 \mathrm{ml}$ (27). They found a level of HE4 with a high rate of predicting optimal cytoreduction in a study with primary laparoscopic approach followed by primary debulking surgery or NACT (27). Another study described that the combination of HE4 and CA125 expression in plasma might predict the surgical outcome in advanced ovarian cancer patients and found higher HE4 levels and CA125 levels in patients with suboptimal cytoreduction (28). A previous study described pretreatment analysis of HE4 as a superior factor than CA125 in differential diagnosis of ovarian cancer type I and II (29). HE4 is superior to CA125 in detecting ovarian cancers type II, but none of these factors seems to be an effective diagnostic tool for type I ovarian cancers (29). Further studies are required. Due to the retrospective character of our study unfortunately HE4 was not determined in our group. HE4 seems to be an important factor in preoperative evaluation of cytoreduction, but should be combined with other factors (27).

Standard of care in ovarian cancer is primary debulking surgery followed by adjuvant platinum-based chemotherapy $(1,2)$. A previous study demonstrated that in patients with primarily inoperable advanced ovarian cancer who got neoadjuvant chemotherapy followed by interval debulking surgery have no inferior benefit compared to patients with primary debulking surgery $(1,2,30)$. The most important factor is complete cytoreduction $(1,2,30)$ and optimal treatment is still discussed. Yet, there is no reliable non-invasive assessment to predict optimal cytoreduction and to avoid suboptimal debulking in advanced ovarian cancer. Previous studies evaluated CA125 level, radiologic techniques (CT/PET-CT) to optimize predicting optimal cytoreduction to stratify patients to interval debulking surgery vs. neoadjuvant chemotherapy and evaluated the role of laparoscopy-based scores in management of advanced ovarian cancer (31). More recently, laparoscopy has been proposed as a reliable predictor of complete cytoreduction (31). They concluded that laparoscopy offers assessment for optimal surgery in advanced ovarian cancer and presented Fagotti laparoscopy-based score as a useful predictor of optimal cytoreduction better than other clinical parameters (31).

A prospective study identified 3 clinical and 6 radiologic criteria significantly associated with suboptimal debulking (19). One criterium was CA125 $\geq 500 \mathrm{U} / \mathrm{ml}$ (19). The combination of these criteria in a prognostic model had a predictive accuracy of 0.758 (19) and might be useful for treatment planning. Other groups described that the evaluation of their CONATS index (a novel index for preoperative, non-invasive prediction of complete primary cytoreduction in advanced ovarian cancer) combined with radiological (CT-scan, ultrasound) and/or laparoscopic findings may improve the assessment of optimal treatment strategy in patients with advanced epithelial ovarian cancer to predict optimal cytoreduction (32). This new index of non-invasive parameters should be used combined with clinical and radiologic findings as recommended in our analysis.

The Fagotti-score is a laparoscopic model for prediction of incomplete cytoreduction in advanced epithelial ovarian cancer (33). The updated score showed a lower rate of inappropriate laparotomic explorations (33), so laparoscopy improves further management in these patients. A previous study demonstrated that CT may be a useful preoperative predictor of suboptimal debulking in advanced ovarian cancer (34). Yet, there is still no final approach to predict optimal cytoreduction.

A previous study evaluates a non-invasive test to predict complete cytoreduction. The serum analysis demonstrates that 
the combination of serum miR-34a-5p and CA 125 could predict surgical outcome in high grade serous ovarian cancer (35). They conclude that 'a molecular test incorporating circulating miRNA to predict completeness of surgical resection has the potential to contribute planning for optimal management (35). Further results are required.

Our data showed a correlation of CA125 level $\geq 500 \mathrm{U} / \mathrm{ml}$ and residual tumour mass (Table III) according to other studies (10). The range of CA125 level associated with optimal cytoreduction was 501-16,062 U/ml (Table II). The correlation of CA125 level and residual tumour mass showed highest median CA125 level in suboptimally debulked patients $(2,347 \mathrm{U} / \mathrm{ml})$ with a range of 502-48,470 $\mathrm{U} / \mathrm{ml}$ compared to patients with complete cytoreduction $(\mathrm{R}=0 \mathrm{~mm})$ and $\mathrm{R}>0 \mathrm{~mm}-\leq 1 \mathrm{~cm}(1,332.5$ vs. $1,250 \mathrm{U} / \mathrm{ml}$; Table II). So optimal cytoreduction can be achieved in individual patients despite very high CA125 levels (Table II). In our study, we demonstrate a significant better prognostic impact on OS and PFS in optimally cytoreduced patients as well (OS: P=0.023; PFS: $\mathrm{P}=0.011$; Table VII; Fig. 1) in the group of CA1 $25<500 \mathrm{U} / \mathrm{ml}$ compared to CA125 $\geq 500 \mathrm{U} / \mathrm{ml}$. Therefore, we could demonstrate that $\mathrm{CA} 125 \geq 500 \mathrm{U} / \mathrm{ml}$ has relevance for frequency of complete cytoreduction and prognosis. These patients might benefit from an initial laparoscopic approach to achieve a histological evidence of disease and to specify resectability to determine how to proceed (primary debulking surgery vs. neoadjuvant chemotherapy) taking into account radiologic findings. Previous studies have shown that CA125 is insufficient as a single predictor for optimal debulking, as seen in our analysis, and several more complex models have since been suggested (14). Another study described CA125 level as a reliable component in preoperative management as a predictor of suboptimal debulking (14). That study demonstrates an optimal cut-off for serum CA125 as a predictor of suboptimal debulking of $586 \mathrm{U} / \mathrm{ml}$ (36), in contrast our cut-off CA125 level was higher in suboptimal debulking (Table III). Arits et al (36) could not find a clear correlation between preoperative serum CA125 levels and suboptimal debulking. They consider the radiologic amount of ascites and considerable weight loss instead of preoperative CA125 values as independent prognostic predictors for suboptimal cytoreduction in patients with advanced ovarian cancer and recommend the discussion of neoadjuvant chemotherapy in these cases (36). A further analysis described that CA125 $\geq 500 \mathrm{U} / \mathrm{ml}$ demonstrated strong association with a risk of suboptimal cytoreduction (37), as seen in our analysis (Table III) and it may be applied in preoperative counseling and treatment planning (37), but an accurate possibility to predict optimal cytoreduction won't work with CA125 level alone (37).

Another study demonstrated preoperative CA125 is a poor, but statistically significant predictive factor for complete cytoreduction after primary cytoreductive surgery, but has no predictive impact on PFS nor OS in a group of high-grade vs. low-grade ovarian cancer patients (38). Our study demonstrated a significant prognostic impact of CA125 level on OS and PFS with CA125 $<500 \mathrm{U} / \mathrm{ml}$ in optimally cytoreduced patients compared to CA125 $\geq 500 \mathrm{U} / \mathrm{ml}$ and demonstrated a higher rate of complete cytoreduction in lower CA125 levels (Table VI), respectively. The comparison of patients with CA125 <500 U/ml vs. CA125 $\geq 500 \mathrm{U} / \mathrm{ml}$ leads to the finding of a comparable rate of suboptimally cytoreduced patients
( $25.7 \%$ vs. $25.8 \%$; Table I), but we could demonstrate a significant better impact on OS and PFS in the group of CA125 $<500 \mathrm{U} / \mathrm{ml}$ leading to a better prognosis (Table VII).

Our analysis demonstrates with CA125 level $\geq 500 \mathrm{U} / \mathrm{ml}$ the higher the CA125 level the higher the suboptimal cytoreduction rate (Table III). The prognostic impact on PFS and OS is worse the higher the CA125 level $(>1,404.5 \mathrm{U} / \mathrm{ml})$, but there is no significant difference (Table IV). Additionally, in the group with CA125 level $\geq 500 \mathrm{U} / \mathrm{ml}$ we could demonstrate that patients with higher CA125 level $(>1,404.5 \mathrm{U} / \mathrm{ml})$ have most often shorter or similar OS and PFS, respectively, regarding the residual tumour mass without significant difference (Table V). To improve rate of optimal debulking and knowing higher suboptimal cytoreduction rate with higher CA125 level, as demonstrated in our analysis (Table III), laparoscopic approach should be mentioned in this context next to clinical and radiological findings.

Another very interesting aspect to CA125 levels and metastases is demonstrated in a previous study. They demonstrated that CA125 stimulates ovarian cancer cell migration via the Wnt signaling pathway (8). Additionally, they evaluated a new cut-off value for serum CA125 $(82.9 \mathrm{U} / \mathrm{ml})$ that may be predictive of metastasis in patients with ovarian cancer (8). This result might be correlated with the known fact that the higher CA125 level more often advanced FIGO stages are found, but further results are still missing.

With discordant data on the impact of CA125 level predicting optimal cytoreduction pretreatment CA125 level should be used in combination with other parameters (clinical and radiologic findings) in defining treatment strategy. This may improve defining optimal treatment strategy in these patients to resolve this clinical dilemma and predict preoperatively which patients with ovarian cancer could be cytoreduced optimally. The current TRUST study (AGO-Ovar) will answer the question of resectability with a two-armed study comparing upfront primary debulking surgery vs. neoadjuvant chemotherapy followed by debulking surgery and will hopefully improve the individualized management and optimize time of surgery. Hopefully, that study will also identify predictive and prognostic biomarkers of resectability/survival and parameters toward a more individualized surgical treatment.

Considering the results of our analysis and those of previous studies, CA125 levels seem to be helpful in predicting suboptimal cytoreductive surgery for patients with primary ovarian cancer, but should be interpreted in association with clinical and radiologic (CT-scan/ultrasound) findings. The higher CA125 levels the lower the rate of optimal cytoreduction in our analysis. In optimally cytoreduced patients pretreatment CA125 $\geq 500 \mathrm{U} / \mathrm{ml}$ has significant worse prognostic impact on OS $(\mathrm{P}=0.023)$ and PFS $(\mathrm{P}=0.011)$ compared to $\mathrm{CA} 125$ $<500 \mathrm{U} / \mathrm{ml}$. The evaluation of clinical and radiological parameter may improve defining the optimal treatment strategy in these patients. At present, there is no sole non-invasive parameter predicting optimal cytoreduction. Perhaps these patients can be chosen by pretreatment CA125 levels. Patients with CA125 $\geq 500 \mathrm{U} / \mathrm{ml}$ may be candidates for initial laparoscopic approach to obtain histologic diagnosis, to evaluate resectability and to determine how to proceed (primary debulking surgery vs. neoadjuvant chemotherapy) taking into account of radiologic findings. 


\section{Acknowledgements}

Not applicable.

\section{Funding}

No funding was received.

\section{Availability of data and materials}

The datasets used and/or analyzed during the current study are available from the corresponding author on reasonable request.

\section{Authors' contributions}

RB made substantial contributions to conception and design, acquisition of data, analysis and interpretation, and was involved in drafting the manuscript and revising it critically for important intellectual content. SB was involved in analysis and interpretation of data, and drafting the manuscript and revising it critically for important intellectual content. AS performed histopathologic analysis of specimen and made substantial contributions to acquisition of data, and was involved in revising the manuscript critically for important intellectual content. BK, RL, AK and DW were involved in analysis and interpretation of data, and drafting the manuscript and revising it critically for important intellectual content. CB made substantial contributions to conception and design, data acquisition, analysis and interpretation of data, and was involved in drafting the manuscript and revising it critically for important intellectual content. All authors read and approved the final manuscript.

\section{Ethics approval and consent to participate}

All patients provided written informed consent prior to inclusion in the evaluation. This investigation was approved by the appropriate ethics committee of University Hospital Tuebingen (May 6, 2015; approval no. 244/2015R) and has therefore been performed in accordance with the ethical standards laid down in the 1964 Declaration of Helsinki.

\section{Patient consent for publication}

All patients provided written informed consent for publication of data.

\section{Competing interests}

The authors declare that they have no competing interests.

\section{References}

1. du Bois A, Reuss A, Pujade-Lauraine E, Harter P, Ray-Coquard I and Pfisterer J: Role of surgical outcome as prognostic factor in advanced epithelial ovarian cancer: A combined exploratory analysis of 3 prospectively randomized phase 3 multicenter trials: By the arbeitsgemeinschaft gynaekologische onkologie studiengruppe ovarialkarzinom (AGO-OVAR) and the groupe d'investigateurs nationaux pour les etudes des cancers de l'Ovaire (GINECO). Cancer 115: 1234-1244, 2009.
2. Vergote I, Tropé CG, Amant F, Kristensen GB, Ehlen T, Johnson N, Verheijen RH, van der Burg ME, Lacave AJ, Panici PB, et al: Neoadjuvant chemotherapy or primary surgery in stage IIIC or IV ovarian cancer. N Engl J Med 363: 943-953, 2010.

3. Bottoni P and Scatena R: The role of CA 125 as tumor marker: biochemical and clinical aspects. Adv Exp Med Biol 867: 229-244, 2015.

4. Sölétormos G, Duffy MJ, Othman Abu Hassan S, Verheijen RH, Tholander B, Bast RC Jr, Gaarenstroom KN, Sturgeon CM, Bonfrer JM, Petersen $\mathrm{PH}$, et al: Clinical use of cancer biomarkers in epithelial ovarian cancer updated guidelines from the European group on tumor markers. Int $\mathbf{J}$ Gynecol Cancer 26: 43-51, 2016

5. Menczer J, Ben-Shem E, Golan A and Levy T: The significance of normal pretreatment levels of CA125 $(<35 \mathrm{U} / \mathrm{ml})$ in epithelial ovarian carcinoma. Rambam Maimonides Med J 6: e0005, 2015.

6. Fader AN, Java J, Krivak TC, Bristow RE, Tergas AI, Bookman MA, Armstrong DK, Tanner EJ and Gershenson DM: The prognostic significance of pre- and post-treatment CA-125 in grade 1 serous ovarian carcinoma: A gynecologic Oncology Group study. Gynecol Oncol 132: 560-565, 2014.

7. Markman M, Federico M, Liu PY, Hannigan E and Alberts D: Significance of early changes in the serum CA-125 antigen level on overall survival in advanced ovarian cancer. Gynecol Oncol 103: 195-198, 2006.

8. Yuan Q, Song J, Yang W, Wang H, Huo Q, Yang J, Yu X, Liu Y, $\mathrm{Xu} \mathrm{C}$ and Bao H: The effect of CA125 on metastasis of ovarian cancer: Old marker new function. Oncotarget 8: 50015-50022, 2017.

9. Randall LM, Sill MW, Burger RA, Monk BJ, Buening B and Sorosky JI: Predictive value of serum CA-125 levels in patients with persistent or recurrent epithelial ovarian cancer or peritoneal cancer treated with bevacizumab on a Gynecologic Oncology Group phase II trial. Gynecol Oncol 124: 563-568, 2012.

10. Chi DS, Venkatraman ES, Masson V and Hoskins WJ: The ability of preoperative serum CA-125 to predict optimal primary tumor cytoreduction in stage III epithelial ovarian carcinoma. Gynecol Oncol 77: 227-231, 2000.

11. Ghisoni E, Katsaros D, Maggiorotto F, Aglietta M, Vaira M, De Simone M, Mittica G, Giannone G, Robella M, Genta S, et al: A predictive score for optimal cytoreduction at interval debulking surgery in epithelial ovarian cancer: A two- centers experience. J Ovarian Res 11: 42, 2018.

12. Memarzadeh S, Lee SB, Berek JS and Farias-Eisner R: CA-125 levels are a weak predictor of optimally cytoreductive surgery in patients with advance epithelial ovarian cancer. Int J Gynecol Cancer 13: 120-124, 2003.

13. Cooper BC, Sood AK, Davis CS, Ritchie JM, Sorosky JI, Anderson B and Buller RE: Preoperative CA 125 levels: An independent prognostic factor for epithelial ovarian cancer. Obstet Gynecol 100: 59-64, 2002.

14. Brockbank EC, Ind TE, Barton DP, Shepherd JH, Gore ME, A'Hern R and Bridges JE: Preoperative predictors of suboptimal primary surgical cytoreduction in women with clinical evidence of advanced primary epithelial ovarian cancer. Int J Gynecol Cancer 14: 42-50, 2004.

15. Gill SE, McGree ME, Weaver AL, Cliby WA and Langstraat CL: Optimizing the treatment of ovarian cancer: Neoadjuvant chemotherapy and interval debulking versus primary debulking surgery for epithelial ovarian cancers likely to have suboptimal resection. Gynecol Oncol 144: 266-273, 2017.

16. Suidan RS, Ramirez PT, Sarasohn DM, Teitcher JB, Iyer RB, Zhou Q, Iasonos A, Denesopolis J, Zivanovic O, Long Roche KC, et al: A multicenter assessment of the ability of preoperative computed tomography scan and CA-125 to predict gross residual disease at primary debulking for advanced epithelial ovarian cancer. Gynecol Oncol 145: 27-31, 2017.

17. Prat J; FIGO Committee on Gynecologic Oncology: Staging classification for cancer of the ovary, fallopian tube, and peritoneum. Int J Gynaecol Obstet 124: 1-5, 2014.

18. Wimberger P, Lehmann N, Kimmig R, Burges A, Meier W and Du Bois A; Arbeitsgemeinschaft Gynaekologische Onkologie Ovarian Cancer Study Group: Prognostic factors for complete debulking in advanced ovarian cancer and its impact on survival. An exploratory analysis of a prospectively randomized phase III study of the Arbeitsgemeinschaft gynaekologische onkologie ovarian cancer study group (AGOOVAR). Gynecol Oncol 106: 69-74, 2007. 
19. Suidan RS, Ramirez PT, Sarasohn DM, Teitcher JB, Mironov S, Iyer RB, Zhou Q, Iasonos A, Paul H, Hosaka M, et al: A multicenter prospective trial evaluating the ability of preoperative computed tomography scan and serum CA-125 to predict suboptimal cytoreduction at primary debulking surgery for advanced ovarian, fallopian tube, and peritoneal cancer. Gynecol Oncol 134: 455-461, 2014.

20. Barlow TS, Przybylski M, Schilder JM, Moore DH and Look KY: The utility of presurgical CA125 to predict optimal tumor cytoreduction of epithelial ovarian cancer. Int J Gynecol Cancer 16 496-500, 2006.

21. Morales-Vásquez F, Pedernera E, Reynaga-Obregón J, López-Basave HN, Gómora MJ, Carlón E, Cárdenas S, Silva-Ayala R, Almaraz M and Méndez C: High levels of pretreatment CA125 are associated to improved survival in high grade serous ovarian carcinoma. J Ovarian Res 9: 41, 2016.

22. Babic A, Cramer DW, Kelemen LE, Köbel M, Steed H, Webb PM, Johnatty SE, deFazio A, Lambrechts D, Goodman MT, et al: Predictors of pretreatment CA125 at ovarian cancer diagnosis: A pooled analysis in the ovarian cancer association consortium. Cancer Causes Control 28: 459-468, 2017.

23. Zorn KK, Tian C, McGuire WP, Hoskins WJ, Markman M, Muggia FM, Rose PG, Ozols RF, Spriggs D and Armstrong DK: The prognostic value of pretreatment CA 125 in patients with advanced ovarian carcinoma: A Gynecologic Oncology Group study. Cancer 115: 1028-1035, 2009.

24. Chi DS, Zivanovic O, Palayekar MJ, Eisenhauer EL, Abu-Rustum NR, Sonoda Y, Levine DA, Leitao MM, Brown CL and Barakat RR: A contemporary analysis of the ability of preoperative serum CA-125 to predict primary cytoreductive outcome in patients with advanced ovarian, tubal and peritoneal carcinoma. Gynecol Oncol 112: 6-10, 2009.

25. Bai H, Sha G, Xiao M, Gao H, Cao D, Yang J, Chen J, Wang Y, Zhang $\mathrm{Z}$ and Shen $\mathrm{K}$ : The prognostic value of pretreatment CA-125 levels and CA-125 normalization in ovarian clear cell carcinoma: A two-academic-institute study. Oncotarget 7: $15566-15576,2016$.

26. Lee M, Chang MY, Yoo H, Lee KE, Chay DB, Cho H, Kim S, Kim YT and Kim JH: Clinical significance of CA125 level after the first cycle of chemotherapy on survival of patients with advanced ovarian cancer. Yonsei Med J 57: 580-587, 2016.

27. Angioli R, Plotti F, Capriglione S, Aloisi A, Montera R, Luvero D, Miranda A, Cafà EV, Damiani P and Benedetti-Panici P: Can the preoperative HE4 level predict optimal cytoreduction in patients with advanced ovarian carcinoma? Gynecol Oncol 128: 579-583, 2013.

28. Braicu EI, Fotopoulou C, Van Gorp T, Richter R, Chekerov R, Hall C, Butz H, Castillo-Tong DC, Mahner S, Zeillinger R, et al: Preoperative HE4 expression in plasma predicts surgical outcome in primary ovarian cancer patients: Results from the OVCAD study. Gynecol Oncol 128: 245-251, 2013.

29. Gąsiorowska E, Michalak M, Warchoł W,Lemańska A, Jasiński P, Spaczyński M and Nowak-Markwitz E: Clinical application of HE4 and CA125 in ovarian cancer type I and type II detection and differential diagnosis. Ginekol Pol 86: 88-93, 2015.
30. Sioulas VD, Schiavone MB, Kadouri D, Zivanovic O, Roche KL, O'Cearbhaill R, Abu-Rustum NR, Levine DA, Sonoda Y, Gardner GJ, et al: Optimal primary management of bulky stage IIIC ovarian, fallopian tube and peritoneal carcinoma: Are the only options complete gross resection at primary debulking surgery or neoadjuvant chemotherapy? Gynecol Oncol 145: 15-20, 2017.

31. Gómez-Hidalgo NR, Martinez-Cannon BA, Nick AM, Lu KH, Sood AK, Coleman RL and Ramirez PT: Predictors of optimal cytoreduction in patients with newly diagnosed advanced-stage epithelial ovarian cancer: Time to incorporate laparoscopic assessment into the standard of care. Gynecol Oncol 137: 553-558, 2015.

32. Karlsen MA, Fagö-Olsen C, Høgdall E, Schnack TH, Christensen IJ, Nedergaard L, Lundvall L, Lydolph MC, Engelholm SA and Høgdall C: A novel index for preoperative, non-invasive prediction of macro-radical primary surgery in patients with stage IIIC-IV ovarian cancer-a part of the Danish prospective pelvic mass study. Tumour Biol 37: 12619-12626, 2016.

33. Petrillo M, Vizzielli G, Fanfani F, Gallotta V, Cosentino F, Chiantera V, Legge F, Carbone V, Scambia G and Fagotti A: Definition of a dynamic laparoscopic model for the prediction of incomplete cytoreduction in advanced epithelial ovarian cancer: Proof of a concept. Gynecol Oncol 139: 5-9, 2015.

34. Son HM, Kim SH, Kwon BR, Kim MJ, Kim CS and Cho SH: Preoperative prediction of suboptimal resection in advanced ovarian cancer based on clinical and CT parameters. Acta Radiol 58: 498-504, 2017

35. Shah JS, Gard GB, Yang J, Maidens J, Valmadre S, Soon PS and Marsh DJ: Combining serum microRNA and CA-125 as prognostic indicators of preoperative surgical outcome in women with high-grade serous ovarian cancer. Gynecol Oncol 148: 181-188, 2018.

36. Arits AH, Stoot JE, Botterweck AA, Roumen FJ and Voogd AC Preoperative serum CA125 levels do not predict suboptimal cytoreductive surgery in epithelial ovarian cancer. Int J Gynecol Cancer 18: 621-628, 2008.

37. Kang S, Kim TJ, Nam BH, Seo SS, Kim BG, Bae DS and Park SY: Preoperative serum CA-125 levels and risk of suboptimal cytoreduction in ovarian cancer: A meta-analysis. J Surg Oncol 101: 13-17, 2010.

38. Muallem MZ, Parashkevova A, Almuheimid J, Richter R, Diab Y, Braicu EI and Sehouli J: Preoperative CA-125 values as a predictive factor for the postoperative outcome in primary serous ovarian cancer. Anticancer Res 37: 3157-3161, 2017.

This work is licensed under a Creative Commons Attribution-NonCommercial-NoDerivatives 4.0 International (CC BY-NC-ND 4.0) License. 